\title{
The African AIDS Epidemic. A History
}

\author{
John Illife \\ Ohio, Ohio University Press, 2006 \\ ISBN: 978-0821416891. \\ Price \$24.95, 210 pages. \\ Walter Kipp \\ Professor, Global Health \\ University of Alberta \\ Edmonton, Alberta, Canada \\ E-mail: Walter.Kipp@ualberta.ca
}

This book provides an overview of the HIV/AIDS epidemic in Africa with a focus on sub-Saharan African countries, where this epidemic was most severe. Of particular interest is the author's perspective that folds biomedical, epidemiological, social, economic and demographic information into one powerful chronology of the natural history and impact of the HIV infection.

In the first chapters, the book describes the probable origin and spread of the Human Deficiency Virus (HIV) in sub-Saharan Africa. The author explains in detail and with scientific soundness how HIV entered the human population in several sites, the central African site in the DRC being the most important one for HIV-1. His argument that HIV penetrated the human population in central and west Africa at least as early as the 1950s and that rapid urbanization in the $70 \mathrm{~s}$ and $80 \mathrm{~s}$ enabled HIV to become of epidemic proportions has been confirmed. Recently, researchers determined that already around 1900 HIV entered the human population but could not spread due to the poor linkages between remote population groups. The author explains how most likely the first urban spread happened in Kinshasa, Democratic Republic of Congo (DRC), but he also gives good reasons why the epidemic in Kinshasa was not explosive but rather leveled off at a relatively low plateau. He then describes how HIV spread from central Africa to the Eastern African countries. The fascinating part of his explanations are how closely the type and severity of the HIV epidemic is linked to the local cultural and economical patterns and differs markedly between sites, e.g. spreading in Nairobi, Kenya, through commercial sex workers and in Kampala, Uganda, more through casual sexual contacts. He further explains how HIV infection rates in rural areas of southern Africa are extremely high (over 24\% in Zimbabwe) in contrast to Eastern African countries. For example, because excellent transport and communication conditions exist between Harare 
and the rural countryside, and landownership of many citizens both in town and in rural areas as a result of colonial times, facilitated the movements of the population between towns and rural villages.

In chapter 8 and 9 the author talks about the response to HIV/AIDS by International Organizations, the African governments and the African population. One important point he makes here is that the HIV/AIDS epidemic could not have been completely prevented even if the responses would have been more timely and effective. However, the slow and inadequate response to HIV/AIDS by all those above may have accelerated the epidemic and made it more severe. The author points out that World Health Organization (WHO) responded to HIV/AIDS in a delayed and ineffective way because it was preoccupied with internal issues (Change from the Global Program of AIDS to UNAIDS). He asks if the approach by WHO under J. Mann who was allegedly influenced by the US gay community which has over-emphasized individual rights against public good, was the best approach for Africa, as Africa's society is based on community/group understandings and is not as individualistic as North American society. One important observations the author makes is the timing of the HIV/AIDS epidemic which spread most rapidly in the 1990s when Africa suffered an economic decline, when the health care services were falling apart (partly due to Structural Adjustment Programs of the World Bank) and when attention by health officials was on other health priorities such as Unicef's Extended Program of Immunization (EPI).

In chapter 10 the author describes the increased involvement of non governmental agencies (NGOs) in most aspects of care for HIV patients, as governments did little to support their care effort. He refers to the family caregivers as the real heroes who shouldered most of the care responsibilities in the homes under difficult conditions, as they exist in many African countries. The evolution of community-based care programs such as early home-based care programs, for example in Zambia, is described. In chapter 11 he summarizes in details the impact of HIV on the household, community and the general society. This is the most comprehensive part of the book and covers the social and economic impact on households, the issue of orphans and child headed households, the impact on agriculture calling for change in crops. $\mathrm{He}$ links the famine in 2001-3 in southern African countries with HIV and argues that without HIV this famine would have been less pronounced. Another interesting argument that links HIV to famine/poverty is the interruption of skill transfer in agriculture where for example the many orphans were deprived of their skill learning process from their parents.

In the last chapters of the book the author discusses the maturation of the HIV/AIDS epidemic and the success of prevention programs. He uses the example of Uganda for an effective response to combat HIV/AIDS. He debates the controversy of effective ways to change sexual behavior; however he does not take a position. He covers from the incidence - prevalence controversy from 
Rakai district and questions why the HIV prevalence in Kinshasa never rose above 10 per cent in the sexual active population. Finally, he concludes the book with the antiretroviral drugs roll-out giving special attention to the situation in South Africa, where the South African Government has failed to provide this life-saving treatment in time.

This is an excellent book and demonstrates the amazing abilities of the author as a historian to incorporate medical, epidemiological, social, and economical information in a "holistic" framework to discuss the evolution and impact of the HIV/AIDS epidemic. I personally would have liked the author to express more his personal opinions throughout the book. For example in his opinion what were Uganda's most effective public health tools that effectively reduced its HIV prevalence? This book will be an excellent resource for professionals and academics and especially for students who try to grapple with the multiple dimensions of HIV/AIDS issues. It is also useful to lay persons, as it is written in a style easy to understand. This book should be mandatory reading for everybody who studies African public health. 